explicativas, que ayudan al alumno a fijar los referentes prácticos indicativos de una buena la progresión.

En el capítulo tres comienza a describir las acciones técnicas de la lucha, en concreto el Empuje de manos. Introduce por primera vez la practica con el compañero con el fin de dominar las normas de la energía consciente en las diferentes acciones como el ataque (adherir) y la defensa (evadir) "...no se puede aprender mediante dibujos o fotos. Si se intenta aprender el Empuje de manos a partir de fotos o con un contrincante no cualificado, surgirá el defecto conocido como manos resbaladizas y la técnica no será efectiva" (p. 57).

Las energías de las "ocho puertas y los cinco pasos" se desarrollan en el capítulo cuatro. Se refiere a los tipos de energía aplicables en el T’ai Chi. Las formas básicas de energía son cuatro: movilizar, recibir, recoge y golpear y estas se combinan con cuatro direcciones motrices de las manos, constituyendo así las ocho puertas. La técnica del desplazamiento se centra en cuatro pasos básicos: avanzar, atrasar, izquierda, derecha y estos, a su vez, pueden dividirse en catorce pasos. Los cuales describe y planifica, el autor, de forma detallada teniendo presente en todo momento el combate.

Los capítulos cinco y seis son los de más complejidad y extensión. Estudian la aplicación de los principios de la lucha T'ai Chi, una vez que se percibe la energía consciente, buscando otros niveles más complejos y que requieren otras aptitudes y dedicación. Se van a observar dos aplicaciones: una el cultivo individual y otra, más compleja, el control de los demás.

Así, en el capitulo cinco, considera primeramente un orden de aprendizaje secuenciado en ocho partes. Comienza con el estudio de la forma y su división por categorías pasando por la práctica del Ch'i Kung, el espíritu de vitalidad,..., para terminar con la cuestión de conocerse a sí mismo y conocer al enemigo. En segundo lugar, y siendo fiel a su característica pedagógica, realiza un resumen de lo expuesto anteriormente y además incluye un vocabulario con los setenta y dos términos básicos del arte marcial del T'ai Chi, "El lenguaje de este arte es primordial para una compresión plena de la materia a tratar. Una palabra es el símbolo de una idea..." (p.129).

El capítulo seis explica como aplicar las normas del T'ai Chi en el combate. Comienza con los nueve principios del entrenamiento en el arte marcial, deteniéndose en el método de enrollar seda y en las nueve reglas. Realiza un esquema para valorar los progresos del boxeo T'ai Chi, sin olvidad la cuestión de lo duro y lo suave, para terminar con la numeración de los setenta y cuatro movimientos de T'ai Chi de Luang P'ing y un antiguo poema de "poste" universal ("abrazar el árbol") del cual transcribimos una muestra: "el poste universal es una forma mística de arte marcial/ Nunca se puede comprender como se práctica en su totalidad/ Aparece como un abrazo, con una sonrisa en la cara.../ La potencia viene de la respiración/ Estoy relajado sin recurrir a la fuerzal Como nubes flotando al viento por todas partes/..." (p.186).

Para finalizar, consideramos que es un libro apropiado para los practicantes que profundizan en el T'ai Chi como arte marcial y que quieren progresar y descubrir nuevos niveles de energía consciente, ya que revela numerosas claves sobre las que trabajar. Es de destacar también el tono científico que el autor utiliza cuando explica biomecánicamente las acciones técnicas más eficaces para el combate. Sin embargo, y a pesar de la cantidad y profundidad de conceptos contenidos en esta obra, estos son diversos en cuanto a su complejidad, por lo que puede ser un libro apropiado también para el principiante que busca el sentido y la práctica de la energía consciente.

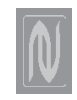

\section{Aikido. Etiqueta y transmisión}

Por Nobuyoshi Tamura

Badalona: Paidotribo, 2002

158 páginas, $21,5 \times 15 \mathrm{~cm}$. Ilustraciones

I.S.B.N.: 84-8019-650-5 • $10 €$

Disponible en:

Editorial Paidotribo

Polígono Les Guixeres

C / de la Energía, 19-21

08915 Badalona (España)

Tel: +34933233311

Fax: +34934535033.

E-mail: paidotribo@paidotribo.com

http://www.paidotribo.com/

Revisión por José Santos Nalda Albiac
A partir de los años 70 el Aikido ha experimentado una considerable difusión en toda Europa, y dado que sus raíces y contexto cultural japonés proceden de la tradición del Budo, no muy bien conocida por los occidentales, el libro viene a llenar este vacío señalado por los mismos practicantes.

Una de las figuras más importantes para la promoción del Aikido en Europa ha sido indudablemente el maestro Tamura, quien llegó a Francia en 1964 tras haber aprendido este Arte directamente del propio fundador, Morihei Ueshiba. Actualmente el Maestro Tamura es $8^{\circ}$ Dan por el Aikikai de Tokio y sigue difundiendo el Aikido. Personalmente, he tenido el placer de conocerle y verle actuar en diversas ocasiones desde el año 1977, asistiendo a los cursos nacionales que se organizaban en Madrid, Santander, Zaragoza, etc. durante diez o doce años y asistiendo en alguna ocasión a los Stages internacionales organizados en Francia, de modo que he visto de cerca su gran maestría y experiencia en el tatami y su buen talante y humanidad fuera de él, por lo que siento agradecimiento y admiración hacia su persona, dado que pasé mis exámenes de $1^{\circ}, 2^{\circ}$, y $3^{\circ}$ Dan ante su presencia en el tribunal, como consta en los diplomas correspondientes firmados por él.

El Aikido en la mente de su fundador, y en la convicción de sus discípulos directos, como es el caso del maestro Tamura, no es un simple deporte, sino un arte marcial, y sobre todo una escuela de vida, en la que el comportamiento individual del aikidoka está sujeto a ciertas normas de etiqueta y valores humanos, que facilitan las relaciones sociales, y predisponen al logro de la armonía psicosomática.

Ya desde el principio se constata que este no es un libro de técnicas de combate, dado que su objetivo es enseñar aquellas reglas de cortesía y buenas maneras que han de observarse en todas las manifestaciones del Aikido como son los entrenamientos, las demostraciones públicas, los exámenes, etc.

Comienza con un capítulo dedicado a los profesores, exponiendo con sencillez y brevedad cómo debe ser el profesor y qué se espera de su tarea y de su persona, como buen eslabón de la cadena encargada de transmitir este Arte.

Un poco más adelante explica de qué manera se ha de enseñar el Aiki- 
do, según la metodología personal del maestro Tamura, en perfecta simbiosis con la tradición y las formas contemporáneas de enseñanza de las artes corporales, así como de los requisitos o normas que ha de guardar el principiante en el ámbito físico, mental y social.

A partir de aquí el autor aborda las reglas mas elementales de cortesía, respeto y etiqueta que forman parte inseparable de esta disciplina, y que todo practicante ha de conocer e incorporar en su comportamiento, porque escribe el maestro Tamura: "la etiqueta sirve para controlar el ego que busca siempre satisfacer sus instintos primarios, orientando la energía para utilizarla en el sentido mas positivo o provechoso".

En el ámbito del Budo se concede gran importancia al respeto de las formas, porque es el primer paso para adoptar la mejor disposición en el aprendizaje, y conseguir el mayor provecho en los entrenamientos, y en consecuencia describe el modo de saludar con las manos vacías, con un sable, con un jo, en posición de pie o de rodillas, cómo entrar en el dojo y ubicarse en él, etc. etc.

Merece toda la atención el capítulo en el que expone las diferentes maneras de entrenar, fiel exponente de la riqueza y versatilidad con la que se puede abordar la practica de esta ciencia del movimiento y de la no resistencia, sin agotar nunca las fuentes del descubrimiento personal, en cuanto a la táctica, la estrategia, y la búsqueda de la excelencia en cada acción.

Respecto a los capítulos que tratan de la relación con otras artes marciales, la limpieza y los principiantes, sus textos son tan escuetos que no aportan gran cosa al lector, siendo lo más valioso de ellos las excelentes fotografías que los acompañan.

Dedica unas páginas a los grados, aunque se ciñe a dar una breve reseña histórica, y a las reglas establecidas por el Zaidan Hojin Aikikai, para acceder a los mismos, pero dada la importancia que los aikidokas conceden a este aspecto jerárquico, hubiera sido interesante conocer la opinión y los consejos del maestro Tamura respecto al modo en que hoy se conceden, evaluando sólo la parte física y técnica del candidato, e ignorando si posee o no los valores éticos acordes con el espíritu del Aikido y del Budo.

El capítulo dedicado a los exámenes también merece interés por sus acertados consejos a los candidatos respecto al comportamiento a observar antes, durante y después del examen de Cinto Negro, y también por las excelentes secuencias fotográficas que muestran como recibir un diploma, o una distinción de manos del maestro.

La última parte del libro enseña el modo de atarse el cinturón y vestirse la hakama, así como la manera de plegarla una vez terminado el entrenamiento, y también los cuidados que requiere el mantenimiento de la katana.

Aikido. Etiqueta y Transmisión es un libro escrito por un gran maestro, que se caracteriza por la brevedad y la sabiduría de sus palabras, la experiencia de toda una vida dedicada a la enseñanza de este Arte, y la garantía de ser un testigo directo de sus primeros tiempos, aportando en sus páginas lo mas fundamental de la tradición Budo, como es el respeto y la cortesía en el Dojo, y por extensión en todas las relaciones personales.

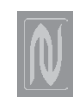

\section{Invitación Al Karate-do (Karate Do Nyu Mon)}

Por Kenwa Mabuni y

Genwa Nakasone

Madrid: Miraguano Ediciones, 2002

208 páginas. $24 \times 17 \mathrm{~cm}$. Ilustraciones

I.S.B.N.: 87-7813-239-2 • $17 €$

Disponible en:

Miraguano Ediciones

C/. Hermosilla, 104

28009 Madrid (España)

Telf.: +34914014645

Fax: +34914021843

E-mail: miraguano@miraguano-sa.es http://www.miraguano-sa.es/

\section{Revisión por Pablo Pereda González}

De encomiable puede calificarse el trabajo de la Editorial Miraguano en su labor de recuperación de obras antiguas sobre Budo, de otro modo inaccesibles al público, como es el caso del libro de referencia escrito por Kena Mabuni, padre del estilo Shito Ryu, y Genwa Nakasone. A este último pocos conocerán por su faceta de editor, redactor y político y sí por su aparición en diversas fotografías con budokas muy conocidos de la época. Quizá la mas conocida y divulgada data del año 36; en ella apa- rece junto a los maestros Kyan, Yabu y Miyagui.

El libro que nos ocupa se compone de dos prólogos; uno del traductor Toshiro Yamaguchi y otro del autor y maestro Mabuni. Lo cierra un epílogo escrito por uno de los hijos del propio maestro: Kenei Mabui. Entre medio 18 capítulos y 55 puntos distribuidos a lo largo de los mismos en cinco partes: "El espíritu Japonés y el Karate-Do”, "El Karate-Do como educación", "Actitud y conocimientos previos a la práctica del Karate-Do", "Ejercicios complementarios y sus instrumentos", y "El Kata Heian Nidan”.

Ya desde el prólogo de Mabuni se deja bien claro el propósito del libro, que no es otro que la difusión del Arte por todo Japón. Funakoshi ya se había establecido allí desde el año 1922 y por tanto el propio Mabubi preparaba su llegada de la mejor manera posible, aunque para ello tuviese que cuestionar al propio Funakoshi por un lado y por otro la propia esencia y origen del Karate-Do. Mabuni hace especial hincapié en las raíces japonesas de la propia Okinawa lo cual, sin duda, pudo generar discrepancias con muchos otros maestros. Todo esto lo puede encontrar el lector en los primeros capítulos del libro.

Llama la atención la actitud de Nakasone en las seis "Consideraciones Preliminares" que aparecen inmediatamente después del prólogo. En un acto de respeto supremo a Mabuni se atribuye toda la responsabilidad sobre los posibles errores que se pudiesen deslizar. Aún permaneciendo el planteamiento confuso, quizá con toda intención, estos posibles errores se refieren a la parte técnica y no a la redacción del pensamiento de Mabuni.

Técnicamente la obra no aporta nada novedoso; tampoco es ese su objetivo, ya que de lo que se trata es dar a conocer un facsímil del año 1938 que servirá, sin duda, como materia de investigación a todos los estudiosos de las raíces del Karate-Do. El aspecto técnico se basa en los Kata "Heian Nidan" y "Sandan", incluyendo sus bunkais, que se desarrollan mediante dibujos a partir del el capítulo 13. Las explicaciones son valiosas dentro del contexto del año en que fue publicado el libro; en el presente son confusas para el neófito; no así las explicaciones teóricas.

El capítulo 18, muy interesante por cierto, versa sobre preguntas formula- 